\title{
Day-to-day variability of the equatorial electrojet current in the South American sector
}

\author{
R. G. Rastogi \\ Physical Research Laboratory, Ahmedabad 380009, India \\ (Received October 13, 2006; Revised February 2, 2007; Accepted February 3, 2007; Online published June 8, 2007)
}

\begin{abstract}
A comparison of the geomagnetic $\mathrm{H}$ field data at Ancon, Peru and Buriticupa, Brazil for the period December 1990 and January 1991 revealed the presence of a significant correlation in day-to-day variability in the solar daily variation of $\mathrm{H}$ at the two stations, which are separated by about $2000 \mathrm{~km}$. It is suggested that the day-to-day variability in the time as well as in the magnitude of the daily peak of the $\mathrm{H}$ field at an equatorial electrojet station is due to the superimposition of a semi-diurnal wave of the electric field over the normal mean daily variation.
\end{abstract}

Key words: Equatorial electrojet, day-to-day variability, equatorial electric field.

\section{Introduction}

The large solar daily range of the horizontal component of the geomagnetic field, $\mathrm{H}$, at stations close to the dip equator have assumed great importance due to its close association with solar weather conditions. Baker and Martyn (1953) showed that the orthogonality of the electric and magnetic field over the dip equator generates large eastward conductivities during the daytime causing the flow of the equatorial electrojet (EEJ) with the normal Sq electric field.

The day-to-day variability of the time and intensity of EEJ at any station has been a puzzling problem, the solution of which is still not clear. Statistical correlations between the day-to-day variation of EEJ strength and solar wind parameters have been demonstrated (Rastogi and Chandra, 1974), but no correlations on individual day has been isolated.

James and Rastogi (2002) studied the relationship between the day-to-day fluctuations in the horizontal geomagnetic field, $\mathrm{H}$, at a chain of 13 stations within a narrow longitude belt in the Indo-Russian sector spanning from the equator to about $60^{\circ} \mathrm{N}$ dip latitude. They showed that the correlation coefficient between the daily ranges of $\mathrm{H}$ at the EEJ station Trivandrum with the corresponding range of $\mathrm{H}$ at other stations dropped rapidly with increasing latitude. For a very quiet period, the correlation coefficient dropped to 0.5 at about $8^{\circ}$ dip latitude and to 0.0 at $11^{\circ}$ dip latitude.

Greener and Schlapp (1979) studied the day-to-day variability of $\mathrm{SqH}$ in the middle latitudes and reported that the spatial scale was of the order of $2000 \mathrm{~km}$.

Rigoti et al. (1999) discussed the morphology of EEJ based on the close array of 29 vector magnetometers operating in N-NE Brazil from November 1990 to January 1991. Rigoti (1994) reported the hourly mean $\mathrm{H}$ and $\mathrm{Z}$ values at 16 selected quiet days for all of these stations. These data have

Copyright (c) The Society of Geomagnetism and Earth, Planetary and Space Sciences (SGEPSS); The Seismological Society of Japan; The Volcanological Society of Japan; The Geodetic Society of Japan; The Japanese Society for Planetary Sciences; TERRAPUB. been used in conjunction with the corresponding data from Ancon, Peru in this paper with the aim of studying the dayto-day variations of both the time as well as the intensity of the EEJ current on the morning-counter (C)EJ, afternoonCEJ, weak midday-EEJ, and strong midday-EEJ and on the EEJ with peak $\Delta \mathrm{H}$ delayed from the midday hours. Comparative studies of daily variations of $\Delta \mathrm{H}$ on the afternoon CEJ and on normal EEJ have been described earlier (Bhargava and Sastri, 1977; Alex et al., 1986).

\section{Results}

Figure 1 shows the mean daily variations of $\mathrm{H}$ averaged on the 16 selected quiet days for Buriticupa in Brazil $\left(\mathrm{H}=26445 \mathrm{nT}, \mathrm{I}=0.23^{\circ} \mathrm{N}\right)$ and for Ancon $(\mathrm{H}=26772 \mathrm{nT}$, $\mathrm{I}=1.2^{\circ} \mathrm{N}$ ). Daily variations of $\mathrm{H}$ on some days at these stations are also shown in the diagram. The daily mean $\Delta H$ at Ancon (ANC) attained its maximum value of $165 \mathrm{nT}$ at $1130 \mathrm{LT}$, while $\Delta \mathrm{H}$ at Buriticupa (BUR) had a maximum value of $153 \mathrm{nT}$ at $1200 \mathrm{LT}$. It is to be noted that the strength of the EEJ was stronger in Peru than in Brazil despite the mean $\mathrm{H}$ field being almost the same at the two places.

The daily variations of $\mathrm{H}$ were very similar on the same day at both stations. On 11 December 1990, the peak H at both the stations was delayed by more than $2 \mathrm{~h}$ and the EEJ at BUR was the weakest of all the days. On 7 January 1991, an extraordinarily large CEJ event occurred during the early morning hours at both the stations; the peak midday values of $\mathrm{H}$ at either of the stations was delayed by more than $2 \mathrm{~h}$ and was larger than the normal value for the hour. On 29 January 1991, the CEJ was observed at both the stations in the afternoon hours. On 30 January 1991, the peak $\Delta H$ values occurred at normal times but were extraordinarily large at both the stations.

Thus, it can be concluded that the daily variations of $\mathrm{H}$ field at both the EEJ stations ANC and BUR separated by about $2000 \mathrm{~km}$ were very similar to each other on any of the days considered in this study.

To understand the cause of the day-to-day variations in 


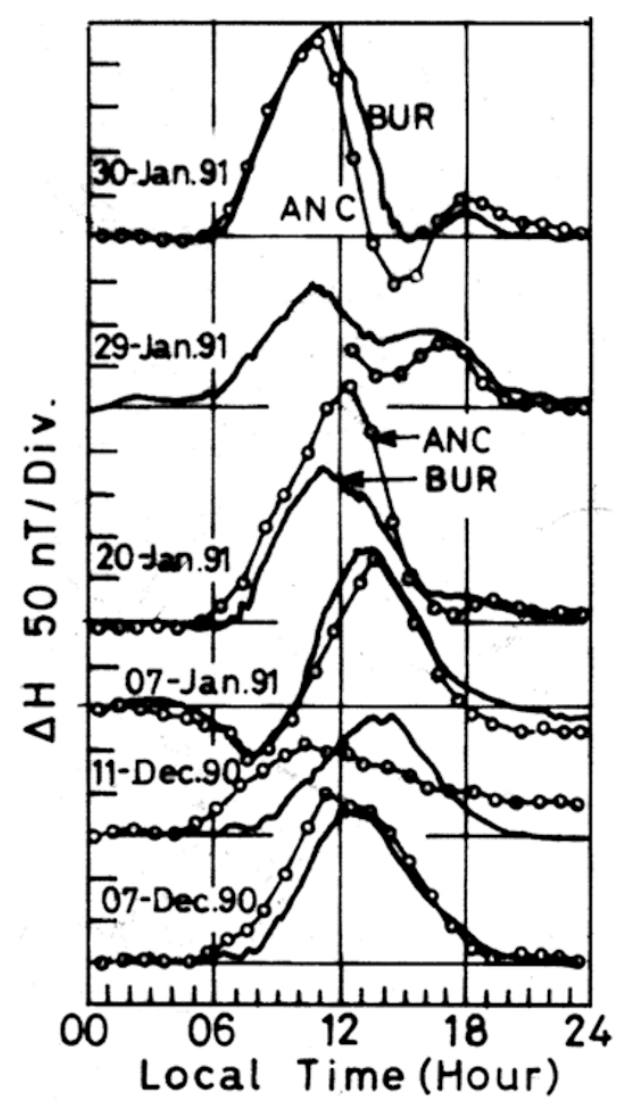

Fig. 1. Daily variations of $\Delta \mathrm{H}$ at ANC and BUR on some of the days between December 1990 and January 1991.

the diurnal characteristics of $\Delta \mathrm{H}$ at BUR, we subtracted the daily variation, $\mathrm{Hm}$, averaged over all 16 days from the daily variation of $\mathrm{H}$ on the individual day. The derived variations of $(\mathrm{H}-\mathrm{Hm})$ at BUR on the selected six days are shown in Fig. 2. We selected the vertical field, Z, data at another station, Braganca $\left(\mathrm{BRA}, \mathrm{I}=6.2^{\circ}\right.$ ), which is situated at the northern edge of the electrojet belt. Any increase (decrease) of $\Delta \mathrm{H}$ at BUR due to the EEJ current would cause a decrease (increase) of $\triangle \mathrm{Z}$ at BRA. The variations of $\triangle Z$ at BRA can be used to confirm the changes in EEJ at BUR. The daily variations of $\Delta(\mathrm{Z}-\mathrm{Zm})$ at BRA are also included in Fig. 2.

It is interesting to note that there was a strong and clear semi-diurnal wave on each of the days $(\mathrm{H}-\mathrm{Hm})$ at BUR which was opposite in phase to the variation of $(\mathrm{Z}-\mathrm{Zm})$ at BRA. This clearly indicates that the day-to-day fluctuations of the EEJ are due to the superimposition of a semi-diurnal current over the monthly mean current. Depending on the phase of the wave, a peak at noon would produce an unusually large daily range of $\mathrm{H}$, as occurred on 30 January 1991. A minimum near the midday would decrease the daily range, as occurred on 11 December 1990. The minima of the semi-diurnal wave occurring in the morning or evening hours, when the normal values of $\Delta H$ are small, would produce a full or partial CEJ.

\section{Discussion}

A comparison of these results with those of Greener and Schapp (1979) suggest that the longitudinal spatial scale of

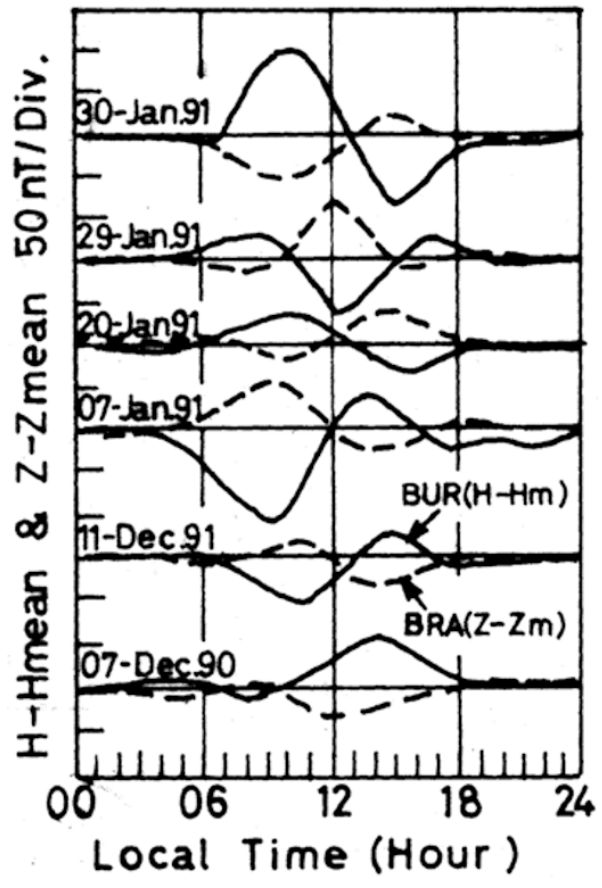

Fig. 2. Daily variations of $\Delta(\mathrm{H}-\mathrm{Hm})$ at BUR and $\Delta(\mathrm{Z}-\mathrm{Zm})$ at BRA on some selected days between December 1990 and January 1991.

day-to-day variability at the equatorial latitudes is of the same order-about $2000 \mathrm{~km}$ - as that at the middle latitudes. However, the results of James and Rastogi (2002) showed that the latitudinal spatial scale of day-to-day variability is comparative small at equatorial latitudes.

The quiet day variations of $\Delta \mathrm{H}$ at any equatorial station is due to the combined effect of conductivity and the electric field, the former being directly related the ionization density of the $\mathrm{E}$ region. The only study of $\Delta \mathrm{H}$ at any equatorial electrojet station in relation to the $\mathrm{E}$ region peak ionization density, $\mathrm{N}_{\max } \mathrm{E}$, has been described by Rastogi (1993) and by Chandra et al. (2000) for the Huancayo and Kodaikanal stations. These investigators showed that the solar cycle variation of $\Delta \mathrm{H}$ at either of the stations was due to the corresponding variations of $\mathrm{E}$ region peak electron density, $\mathrm{N}_{\max } \mathrm{E}$. The seasonal variation corrected for $\mathrm{N}_{\max } \mathrm{E}$ was shown to be related to the corresponding variation of the $\mathrm{E}$ region electric field. The daily variation of $\mathrm{N}_{\max } E$ showed a maximum at local noon, while the electric field $\mathrm{E}$ at electrojet station Thumba (close to Kodaikanal) peaked at around $1000 \mathrm{LT}$, causing the peak $\Delta \mathrm{H}$ at around $1100 \mathrm{LT}$. The E region was shown to be very regular in respect to diurnal and seasonal solar cycle variations. Thus, the day-to-day variations of $\Delta H$ were attributed to the corresponding variations of the ionospheric electric field. Rastogi and Chandra (1974) have demonstrated the close relation between the quiet day electric field and the component of interplanetary field normal to the ecliptic.

The present analysis showing the correspondence in the short-period fluctuations in $\Delta \mathrm{H}$ at Ancon and Buriticupa in local time and not in universal time suggests that the source of these events are moving with time. The EEJ is very sensitive to electric fields generated by the solar or lunar systems due to planetary waves as well as the electric fields 
communicated to the equator by solar wind interactions with the earth magnetosphere.

Acknowledgments. Grateful thanks are due to Dr. A. Rigoti for sending me his $\mathrm{PhD}$ thesis which formed the basis of this study. Thanks are due to Dr. Matsumi Istitsuka for providing the geomagnetic data at Ancon, to the Physical Research Laboratory for the infrastructural facilities, and to Indian Space Research Organization for the research grant to the author. Thanks are also due to Prof. H. Chandra for discussions during the course of the study.

\section{References}

Alex, S., A. R. Patil, and R. G. Rastogi, Equatorial counter electrojet solution of some dilemma, Ind. J. Radio. Space. Phys., 15, 114-118, 1986.

Baker, W. G. and D. F. Martyn, Electric currents in the ionosphere. The conductivity, Phil. Trans. R. Soc. Lond., A246, 281-294, 1953.

Bhargava, B. N. and N. S. Sastri, A comparison of days with and without occurrence of counter electrojet afternoon events in the Indian region, Ann. Geophys., 33, 329-333, 1977.
Chandra, H., H. S. S. Sinha, and R. G. Rastogi, Equatorial electrojet studies from rocket and ground measurements, Earth Planet Space, 52, 111120, 2000.

Greener, J. G. and D. M. Schlapp, A study of day to day variability of Sq over Europe, J. Atmos. Terr. Phys., 41, 217-223, 1979.

James, M. E. and R. G. Rastogi, Critical study of the solar daily range of geomagnetic $\mathrm{H}$ field as Indo-Russian chain of stations, J. Ind. Geophys. Union, 4(4), 182-194, 2002.

Rastogi, R. G. and H. Chandra, Interplanetary magnetic field and the equatorial ionosphere, J. Atmos. Terr. Phys., 36, 377-379, 1974.

Rastogi, R. G., Geomagnetic field variations at low latitudes and ionospheric electric fields, J. Atmos. Terr. Phys., 55, 1375-1381, 1993.

Rigoti, A., Geomagnetic array study of the EEJ in N-NE Brazil. Ph.D. Thesis, School of Earth Sciences, Flinders University of South Australia, 1994.

Rigoti, A., F. H. Chamaluan, N. B. Trivedi, and A. L. Padilha, Characteristics of the equatorial electrojet determined from an array of magnetometers in N-NE Brazil, Earth Planet. Space, 51, 115-128, 1999.

R. G. Rastogi (e-mail: profrgrastogi@yahoo.com) 